\title{
Student Editorial Board for Volume 23
}

Student Editorial Board members are appointed by members of the Editorial Board to serve for at least 1 year. Student members independently review manuscripts which are also sent to their sponsoring board members. Participation on the board provides students with experience in the review process and provides authors of manuscripts with additional feedback. During the past year the following students offered generously of their time to serve the journal as members of the Student Editorial Board. We are grateful for the contribution that each one has made to Law and Human Behavior.

David Battin, Department of Human Development, Cornell University Amy Bradfield, Department of Psychology, Iowa State University Anne Connell, Institute of Criminology, Cambridge University Jessica Cousineau, College of Law, University of Arizona Angela Crossman, Department of Human Development, Cornell University Robert S. Done, Management and Policy Department, University of Arizona John Edens, Department of Law and Mental Health, University of South Florida Carrie S. Fried, Department of Psychology, University of Virginia Simara Ghetti, Department of Psychology, University of California Susan Greene, Department of Psychology, University of California-Santa Cruz Michelle Guyton, Department of Psychology, University of Utah Amy Hackney, Department of Psychology, Saint Louis University Tamara Haegerich, Department of Psychology, University of Illinois-Chicago Ivan Haskell, Department of Psychology, University of South Carolina Jennifer Hunt, Department of Psychology, University of Minnesota Michael Johns, Department of Psychology, University of Colorado Karen Kadela, Department of Psychology, Saint Louis University Antoinette Kavanaugh, Department of Psychiatry, University of Massachusetts Medical School

Marc Klippenstine, Department of Psychology, York University

Tim Lavery, Department of Criminal Justice, Loyola University-Chicago

Bradley D. McAuliff, Department of Psychology, Florida International University Christian Meissner, Department of Psychology, Florida State University Kim S. Menard, Department of Sociology, Pennsylvania State University Tony Palmer, Department of Mental Health Law and Policy, University of North Carolina-Chapel Hill

731 
Dawn Peusehold, Department of Psychiatry, University of Massachusetts Medical School

Shannon Rauch, Department of Psychology, Saint Louis University

Aaron Rudnicki, Department of Psychology, University of Illinois-Chicago

Melinda G. Schmidt, Department of Psychology, University of Virginia

Hope Seib, Department of Psychology, Saint Louis University

Jennifer N. Shaffer, Department of Sociology, Pennsylvania State University

Colleen Sinclair, Department of Psychology, University of Minnesota

Jennifer Skeem, Department of Psychology, University of Utah

Samuel R. Sommers, Department of Psychology, University of Michigan

Karen Ustad, Department of Psychiatry, University of Massachusetts Medical School

Elizabeth Vorndran, Department of Psychology, Iowa State University

Laura Warren, Department of Psychology, Saint Louis University

Adina Wasserman, Department of Psychology, Florida State University

Teri White, Department of Psychology, North Carolina State University

Lisa Willoughby, Department of Psychology, Saint Louis University

W. Douglas Woody, Department of Psychology, University of Colorado

Meagan Yarmey, Department of Psychology, York University 